\title{
Ingested capsaicinoids can prevent low-fat-high- carbohydrate diet and high-fat diet-induced obesity by regulating the NADPH oxidase and Nrf2 pathways
}

This article was published in the following Dove Press journal:

Journal of Inflammation Research

13 November 2017

Number of times this article has been viewed

\section{Kazim Sahin' \\ Cemal Orhan' \\ Mehmet Tuzcu \\ Nurhan Sahin' \\ Oguzhan Ozdemir ${ }^{2}$ \\ Vijaya Juturu ${ }^{3}$}

'Department of Animal Nutrition, Veterinary Faculty, Firat University, Elazig, Turkey; ${ }^{2}$ Department of Biology, Faculty of Science, Firat University, Elazig, Turkey; ${ }^{3}$ Scientific and Clinical Affairs, Research and Development, OmniActive Health Technologies, Inc., Morristown, NJ, USA
Correspondence: Kazim Sahin Department of Animal Nutrition, Veterinary Faculty, Firat University, Zubeyde Hanim Cad, Elazig 23119,

Turkey

Tel+90 5327473506

$\mathrm{Fax}+904242388173$

Email nsahinkm@yahoo.com
Objective: Capsaicinoids (CAPs), most commonly found in chili peppers, have a multitude of pharmacological and physiological effects, such as anti-inflammation, antioxidant, and anticancer effects. In the present study, we set out to investigate the hypothesis that CAPs mitigate obesity in rats and the possible mechanisms thereof.

Materials and methods: Rats were divided into six groups, including control $( \pm 10 \mathrm{mg}$ CAPs/ $\mathrm{kg}$ body weight $[\mathrm{BW}])$, low-fat-high-sucrose diet $( \pm 10 \mathrm{mg} \mathrm{CAPs} / \mathrm{kg} \mathrm{BW})$, and high-fat $\operatorname{diet}( \pm 10$ $\mathrm{mg} \mathrm{CAPs} / \mathrm{kg} \mathrm{BW}$ ). Blood samples and liver and aortic tissues were taken at the end of the study. Results: CAPs supplementation significantly reduced hyperglycemia and hyperlipidemia $(P<0.001)$ and ameliorated oxidative damage by reducing malondialdehyde concentrations in serum and liver and by increasing total antioxidant capacity in serum induced by the low-fat-highsucrose and high-fat diets $\left(P<0.001\right.$ for all). CAPs also depressed levels of NFKB p65, gp 91 ${ }^{\text {phox }}$, and $\mathrm{p} 22^{\text {phox }}$, essential components of NADPH oxidase, in the aorta of rats. However, levels of Nrf2, Sirt1, and endothelial nitric oxide synthase were significantly increased in the aorta.

Conclusion: CAPs may at least partially reduce adverse effects due to high-fat diet and sucrose consumption through regulation of energy metabolism, oxidative stress, and proteins involved in vasoprotection.

Keywords: capsaicinoids, metabolism, oxidative stress, lipid profile, antioxidant capacity

\section{Introduction}

Metabolic syndrome is a worldwide health problem with increased morbidity and comprises a group of risk factors such as insulin resistance, obesity, hyperglycemia, hypertension, and dyslipidemia. ${ }^{1-3}$ Metabolic syndrome has been reported to develop due to such factors as a surplus of fat and simple carbohydrates from high-fat diets (HFDs) and high-sucrose diets (HSDs). ${ }^{2,3}$ Experimental models have been studied in detail by our research group on the metabolic changes that result from the consumption of these diets. As a result of our and other studies, these diets have been reported to trigger insulin resistance and promote inflammatory processes, hyperinsulinemia, and hyperlipidemia, and increase blood pressure, hepatic steatosis, and vascular dysfunction. ${ }^{3-6}$ In addition, an association between HFDs and HSDs facilitating oxidative stress and a reduction in nitric oxide levels has been revealed. ${ }^{7}$ In recent years, many studies have been conducted to determine the potential effects of phytochemicals, such as cinnamon, genistein, resveratrol, and capsaicin, on animal models induced 
by HFDs. ${ }^{6,8,9}$ However, there have been no reports on the effects of the molecular mechanism of capsaicinoids (CAPs) in HFDs and HSDs in rats.

CAPs are the major pungent, naturally occurring active compounds in capsicum fruit, such as hot chili peppers (genus Capsicum), with the most abundant forms being capsaicin, dihydrocapsaicin, and nordihydrocapsaicin. ${ }^{10}$ The available information indicates that CAPs possess a wide variety of biological and physiological properties, including antiinflammatory, ${ }^{11}$ antioxidant, ${ }^{12}$ and anticancer. ${ }^{13}$ Whiting et $\mathrm{al}^{14}$ indicated that CAPs played a beneficial role as part of a weight-management program. Capsicum extract is a CAPenriched standardized product obtained from dried red fruit of C. annuum L. CAPs are responsible for the spicy taste of the chili pepper berry. ${ }^{11}$ They are hydrophobic, colorless, odorless, and crystalline waxy compounds, and their varieties are present in capsicum. The CAPs in the pepper are biosynthesized from branched-chain amino acids and phenylalanine in pepper fruit. In chili pepper, capsaicin is the primary CAP, followed by dihydrocapsaicin, nordihydrocapsaicin, homodihydrocapsaicin, and homocapsaicin. ${ }^{11,15,16}$

Capsicum spp. have been used as a carminative, digestive irritant, stomachic, stimulant, rubefacient, and tonic. ${ }^{16}$ The plants have also been used as folk remedies for dropsy, colic, diarrhea, asthma, arthritis, muscle cramps, and toothache. ${ }^{16,17}$ It has also been reported that consumption of capsaicin promoted fat oxidation in negative energy balance and did not increase blood pressure significantly. ${ }^{18}$ Additionally, capsiate activates TRPV1 receptors in the gut. ${ }^{19}$ Capsicum extract is also used in cosmetic products, where it functions as an external analgesic, flavoring agent, fragrance component, or skin-conditioning agent. ${ }^{15,16,20}$ Therefore, the present study was undertaken in an animal model to investigate the effects of CAPs on lipid profile, metabolic health risk factors, and oxidative stress markers, and explored the possible mechanisms in the aorta of rats fed healthy or unhealthy diets.

\section{Materials and methods}

\section{Animals}

A total of 42 male Wistar rats (age 8 weeks, weight $180 \pm 20 \mathrm{~g}$ ) were housed in a controlled standard laboratory environment (12:12-hour light:dark cycle at $22^{\circ} \mathrm{C}$ ) and fed with rat chow and HFD diets, and had water ad libitum. All experiments were conducted under the National Institutes of Health's Guide for the Care and Use of Laboratory Animals and approved by the ethics committee of Firat University, Elazig, Turkey. The composition of diets (control and HFD) is shown in Table 1.
Table I Composition of diets $(\mathrm{g} / \mathrm{kg})$ fed to rats

\begin{tabular}{lll}
\hline Items & Control & High-fat diet \\
\hline Casein & 200.0 & 200.0 \\
Starch & 579.5 & 150.0 \\
Sucrose & 50.0 & 149.5 \\
Soybean oil & 70.0 & 0 \\
Beef tallow & 0 & 400.0 \\
Cellulose & 50.0 & 50.0 \\
Vitamin-mineral premix* & 45.0 & 45.0 \\
I-Cysteine & 3.0 & 3.0 \\
Choline bitartrate & 2.5 & 2.5 \\
\hline
\end{tabular}

Notes: *The vitamin-mineral premix provides the following (per $\mathrm{kg}$ ): all-trans-retinyl acetate $1.8 \mathrm{mg}$; cholecalciferol $0.025 \mathrm{mg}$; all-rac- $\alpha$-tocopherol acetate $12.5 \mathrm{mg}$; menadione sodium bisulfate $\mathrm{I} . \mathrm{I} \mathrm{mg}$; riboflavin $4.4 \mathrm{mg}$; thiamine mononitrate $1.1 \mathrm{mg}$; vitamin $B_{6} 2.2 \mathrm{mg}$; niacin $35 \mathrm{mg}$; Ca-pantothenate $10 \mathrm{mg}$; vitamin $B_{12} 0.02 \mathrm{mg}$; folic acid $0.55 \mathrm{mg}$; d-biotin $0.1 \mathrm{mg}$; manganese (from manganese oxide) $40 \mathrm{mg}$; iron (from iron sulfate) $12.5 \mathrm{mg}$; zinc (from zinc oxide) $25 \mathrm{mg}$; copper (from copper sulfate) $3.5 \mathrm{mg}$; iodine (from potassium iodide) $0.3 \mathrm{mg}$; selenium (from sodium selenite) 0.15 $\mathrm{mg}$; choline chloride $175 \mathrm{mg}$.

\section{Experimental diets and design}

After 1 week of acclimation to a standard rodent-chow diet, 42 rats were randomly allocated into six groups, with seven rats in each group: controls, rats fed chow diet $(12 \%$ of calories as fat); CAPs, rats fed chow diet and administered CAPs (Cap$\operatorname{simax}^{\circledR}$ [OmniActive Health Technologies, Ltd., Morristown, NJ, USA]; $10 \mathrm{mg} / \mathrm{kg}$ body weight [BW], $0.2 \mathrm{mg}$ CAPs); HSD, rats fed chow diet plus $20 \%$ sucrose $(30 \% \mathrm{w}: \mathrm{v})$ in the drinking water, ${ }^{21,22}$ HSD + CAPs, rats fed chow diet plus $20 \%$ sucrose $(30 \% \mathrm{w}: \mathrm{v})$ in the drinking water and administered CAPs (Capsimax; $10 \mathrm{mg} / \mathrm{kg} \mathrm{BW,} 0.2 \mathrm{mg}$ CAPs); HFD, rats fed an HFD ( $42 \%$ of calories as fat); and HFD + CAPs, rats fed an HFD and administered CAPs (Capsimax; $10 \mathrm{mg} / \mathrm{kg} \mathrm{BW}, 0.2$ mg CAPs). Rats were treated orally with CAPs $(10 \mathrm{mg} / \mathrm{kg} \mathrm{BW}$ dissolved in $5 \%$ dimethyl sulfoxide) daily by oral gavage to the end of the experiment. Capsimax consists of CAPs obtained from dried red fruit of $C$. annum $\mathrm{L}$. The product is standardized to $2 \%$ CAPs, of which $1.2 \%-1.35 \%$ is capsaicin, $0.6 \%-0.8 \%$ dihydrocapsaicin, and $0.1 \%-0.2 \%$ nordihydrocapsaicin. CAP concentrate was provided by OmniActive Health Technologies, Ltd., (Morristown, NJ, USA). The dosage of CAPs chosen was based on previously reported dosage in rodents. ${ }^{23}$ Animals were administered CAPs for 8 weeks. HFDs were prepared weekly in our laboratory in pellets and stored at $-4^{\circ} \mathrm{C}$.

\section{Sample collection}

At the end of the experimental period, rats were weighed and then killed by decapitation. Blood samples were collected and serum was prepared by centrifuging the blood at $3,000 \times g$ for 10 minutes, aliquoted into $1.5 \mathrm{~mL}$ vials, frozen at $-80^{\circ} \mathrm{C}$, and used for biochemical parameters and malondialdehyde (MDA) analyses. Livers and aortas were carefully 
removed, weighed, and then stored at $-80^{\circ} \mathrm{C}$. Samples $(1 \mathrm{~g})$ were homogenized in $2 \mathrm{~mL}$ TBS buffer $(50 \mathrm{mM}$ Tris- $\mathrm{HCl}$, $150 \mathrm{mM} \mathrm{NaCl}, \mathrm{pH} 7.4$ ) and centrifuged at 3,000 $\times g$ for 15 minutes at $4^{\circ} \mathrm{C}$. Supernatants were collected and used for MDA estimations.

\section{Laboratory analyses}

Serum parameters were determined by an automated analyzer (Labgeo PT10; Samsung Electronics Co, Seoul, South Korea). Levels of insulin and leptin were analyzed with rat insulin and leptin kits (Linco Research, Inc., St Charles, MO, USA) via an enzyme-linked immunosorbent assay device (Elx-800; BioTek Instruments, Inc., Winooski, VT, USA). The assay's sensitivity was 0.18 and $0.26 \mathrm{ng} / \mathrm{mL}$ for insulin and leptin, respectively. Inter- and intra-assay constants were $5.2 \%$ and $6.1 \%$ for insulin and $4.7 \%$ and $6.5 \%$ for leptin, respectively. MDA concentrations in livers and aortas were measured as per the method in Karatepe ${ }^{24}$ via high-performance liquid chromatography with a Shimadzu ultraviolet-visible SPD-10A VP detector, a CTO-10AS VP column, and mobile phase comprising $30 \mathrm{mM} \mathrm{KH}_{2} \mathrm{PO}_{4}$ and methanol (82.5:17.5 v:v, $\mathrm{pH} 3.6)$ at a flow rate of $1.2 \mathrm{~mL} / \mathrm{min}$. Tissue homogenates $(10 \% \mathrm{w}: \mathrm{v})$ were prepared in $10 \mathrm{mM}$ phosphate buffer $(\mathrm{pH} 7.4$ ) and centrifuged at $13,000 \times g$ for 10 minutes at $4^{\circ} \mathrm{C}$. Total antioxidant capacity (TAC) was measured using dark blue-green color reduction 2,2'-azinobis(3-ethylbenzothiazoline-6-sulfonate) by antioxidants to its colorless form via the antioxidants in the sample. ${ }^{25}$

\section{Western blot analysis}

Levels of NFKB, Nrf2, Sirt1, endothelial nitric oxide synthase (eNOS), gp91 ${ }^{\text {phox }}$, and $\mathrm{p} 22^{\text {phox }}$ in the aortas were analyzed via Western blotting. ${ }^{26}$ Samples were analyzed in quadruplicates for each experimental situation. For this purpose, $50 \mu \mathrm{g}$ of proteins were transferred to a nitrocellulose membrane after electrophoresis (Whatman, Maidstone, UK). The phosphorylated form of antibodies against NFkB, Sirt1, Nrf2, eNOS, gp91 ${ }^{\text {phox }}$, and p22 $2^{\text {phox }}$ proteins (Abcam, Cambridge, UK) were diluted in a concentration of 1:1,000 PBS buffer containing $0.05 \%$ of Tween 20 . The loading of proteins was controlled by a monoclonal mouse antibody versus $\beta$-actin (A5316; Sigma-Aldrich, St Louis, MO, USA). Bands were viewed with ImageJ, an image-analysis system (National Institutes of Health, Bethesda, MD, USA).

\section{Statistical analysis}

Sample size was based on a power of $85 \%$ to obtain $P<0.05$. Differences among groups were evaluated by analysis of variance and Tukey's post hoc analysis. $P<0.05$ was considered statistically significant. Data were analyzed in SPSS for Windows version 20 (IBM, Armonk, NY, USA).

\section{Results}

\section{Body weight and biochemical parameters}

The effects of CAP supplementation on final BW, lipid profile, and safety end markers for liver-function tests are shown in Table 2. HSD and HFD feeding increased final BW, total cholesterol and triglycerides by $10 \%$ and $6 \%, 56$ and $49 \%$, and $182 \%$ and $139 \%$ compared to control rats, respectively $(P<0.001)$. CAP treatment decreased total cholesterol and triglycerides by $17 \%$ and $26 \%$ and $12 \%$ and $19 \%$ in HSD- and HFD-fed rats, respectively $(P<0.001)$. No significant difference in BW $(P>0.05$, Table 2$)$ was observed in the HSD- and HSD-fed rats treated with CAPs $(P>0.05$, Table 2$)$. No significant difference was found either in BW between HFD-fed rats and HFD-fed rats treated with CAPs $(P>0.05$, Table 2$)$. No significant differences were detected in safety end markers for liver-function tests in any treatment $(P>0.05$, Table 2$)$.

As seen in Table 3, HSD and HFD feeding increased serum levels of glucose ( $87 \%$ and $70 \%$ ), insulin (138\% and $61 \%$ ), free fatty acid (FFA; $233 \%$ and 288\%) and leptin (345\% and $103 \%)$ in HSD and HFD rats, respectively $(P<0.001)$. Hypertriglyceridemia and elevated lipid indicators in HSDand HFD-fed rats were reduced with CAP supplementation

Table 2 Effects of capsaicinoids (CAPs) on final BW and plasma biochemical parameters in high-sucrose diet (HSD)- and high-fat diet (HFD)-fed rats

\begin{tabular}{|c|c|c|c|c|c|c|}
\hline \multirow[t]{2}{*}{ Item } & \multicolumn{6}{|l|}{ Groups } \\
\hline & Control & CAPs & HSD & HSD + CAPs & HFD & HFD + CAPs \\
\hline Final BW, g & $289.00 \pm 3.04^{\mathrm{b}}$ & $288.36 \pm 4.24^{b}$ & $318.14 \pm 6.96^{a}$ & $314.86 \pm 3.72^{\mathrm{a}}$ & $307.00 \pm 4.25^{\mathrm{a}, \mathrm{b}}$ & $306.00 \pm 4.65^{a, b}$ \\
\hline TC, mg/dL & $62.14 \pm 1.20^{d}$ & $62.7 I \pm 0.94^{b, c}$ & $97.43 \pm 1.13^{\mathrm{a}}$ & $81.29 \pm 1.23^{b}$ & $92.86 \pm 2.37^{a}$ & $68.71 \pm 1.30^{c}$ \\
\hline TG, mg/dL & $28.57 \pm 0.92^{d}$ & $26.86 \pm 1.28^{d}$ & $80.71 \pm 2.55^{a}$ & $71.43 \pm 1.67^{b}$ & $68.43 \pm 2.44^{\mathrm{b}}$ & $55.00 \pm 2.05^{c}$ \\
\hline ALT, U/L & $75.43 \pm 3.95$ & $74.71 \pm 3.52$ & $79.43 \pm 3.85$ & $77.71 \pm 3.15$ & $80.29 \pm 3.05$ & $76.86 \pm 4.02$ \\
\hline AST, U/L & $|4| .7 \mid \pm 5.62$ & $139.00 \pm 4.69$ & $|45.7| \pm 6.5 \mid$ & $142.57 \pm 3.10$ & $149.14 \pm 6.94$ & $146 \pm 3.70$ \\
\hline
\end{tabular}

Notes: Different superscript letters indicate group mean differences $(P<0.05)$. Data are means $\pm S E$

Abbreviations: ALT, alanine aminotransferase; AST, aspartate aminotransferase; BW, body weight; TC, total cholesterol; SE, standard error; TG, triglycerides. 
Table 3 Effects of capsaicinoids (CAPs) on serum glucose, insulin, FFA, leptin, MDA, TAC, and liver MDA concentrations in highsucrose diet (HSD)- and high-fat diet (HFD)-fed rats

\begin{tabular}{|c|c|c|c|c|c|c|}
\hline \multirow[t]{2}{*}{ Parameters } & \multicolumn{6}{|l|}{ Groups } \\
\hline & Control & CAPs & HSD & HSD + CAPs & HFD & HFD + CAPs \\
\hline Glucose, mg/dL & $96.14 \pm 3.03^{d}$ & $93.71 \pm 1.46^{d}$ & $180.14 \pm 5.57^{a}$ & $147.00 \pm 2.53^{c}$ & $163.43 \pm 3.25^{b}$ & $|37.7| \pm 2.47^{c}$ \\
\hline Insulin, $\mu \mid \mathrm{I} / \mathrm{mL}$ & $26.28 \pm 0.07^{e}$ & $26.06 \pm 0.06^{\mathrm{e}}$ & $62.72 \pm 0.17^{a}$ & $57.72 \pm 0.20^{b}$ & $42.47 \pm 0.14^{c}$ & $36.48 \pm 0.13^{d}$ \\
\hline FFA, $\mathbf{m M}$ & $1.27 \pm 0.05^{d}$ & $1.23 \pm 0.04^{d}$ & $4.23 \pm 0.10^{b}$ & $2.40 \pm 0.1 I^{c}$ & $4.93 \pm 0.08^{\mathrm{a}}$ & $2.34 \pm 0.05^{c}$ \\
\hline Leptin, ng/mL & $13.43 \pm 0.78^{d}$ & $12.71 \pm 1.04^{\mathrm{d}}$ & $59.86 \pm 2.20^{\mathrm{a}}$ & $33.43 \pm 0.72^{b}$ & $27.29 \pm 0.8 \mathrm{I}^{\mathrm{c}}$ & $16.14 \pm 0.59^{d}$ \\
\hline Serum MDA, nmol/mL & $0.82 \pm 0.03^{d}$ & $0.44 \pm 0.0 \mathrm{I}^{\mathrm{e}}$ & $1.76 \pm 0.03^{\mathrm{a}}$ & $1.19 \pm 0.03^{c}$ & $1.33 \pm 0.03^{b}$ & $1.11 \pm 0.02^{c}$ \\
\hline Liver MDA, nmol/mL & $1.84 \pm 0.04^{d}$ & $1.26 \pm 0.04^{\mathrm{e}}$ & $3.64 \pm 0.02^{\mathrm{a}}$ & $2.29 \pm 0.05^{c}$ & $3.19 \pm 0.04^{b}$ & $1.95 \pm 0.05^{d}$ \\
\hline Aorta MDA, nmol/mL & $1.65 \pm 0.07^{d}$ & $1.32 \pm 0.05^{\mathrm{e}}$ & $4.64 \pm 0.15^{a}$ & $2.83 \pm 0.08^{c}$ & $3.55 \pm 0.13^{b}$ & $2.20 \pm 0.08^{d}$ \\
\hline Serum TAC, U/mL & $1.18 \pm 0.02^{b}$ & $1.45 \pm 0.03^{\mathrm{a}}$ & $0.33 \pm 0.02^{f}$ & $0.87 \pm 0.02^{c}$ & $0.50 \pm 0.0 \mathrm{I}^{\mathrm{e}}$ & $0.77 \pm 0.03^{d}$ \\
\hline
\end{tabular}

Notes: Data are means \pm standard error. Different superscript letters indicate group mean differences $(P<0.05)$.

Abbreviations: FFA, free fatty acid; MDA, malondialdehyde; TAC, total antioxidant capacity.

by $18 \%$ and $16 \%$ for glucose, $8 \%$ and $14 \%$ for insulin, $43 \%$ and $52 \%$ for FFA, and $44 \%$ and $40 \%$ for leptin, respectively $(P<0.05)$. Serum and liver MDA levels increased $114 \%$ and 97\% for HSD and $62 \%$ and $73 \%$ for HFD $(P<0.001$, Table 3 ), and serum TAC decreased by $72 \%$ for HSD and $57 \%$ for HFD upon obesity induction. CAP treatment caused a $32 \%$ and $37 \%$ reduction for $\mathrm{HSD}$ and $16 \%$ and $18 \%$ reduction for HFD in serum and liver MDA concentrations and elevation in serum TAC by $163 \%$ and $54 \%$ in the HSD- and HFD-fed rats $(P<0.001)$, respectively, similar to the control group $(P>0.05)$.

\section{Aortic protein levels}

Aortic NFKB, a transcription factor, gp9 $91^{\text {phox }}$, and $\mathrm{p} 22^{\text {phox }}$ (essential components of NADPH oxidase) levels were increased by HFD and HSD intake, whereas HFD- and HSDfed rats had decreased heart Nrf2, an emerging regulator of cellular resistance to oxidants, Sirt1, an important regulator of energy metabolism, and eNOS, a vasoprotective molecule of nitric oxide expression $(P<0.0001$ for all). However, CAPs decreased levels of NFKB, gp9 $1^{\text {phox }}$, and $\mathrm{p} 22^{\text {phox }}$ and increased levels of Sirt1, Nrf2, eNOS significantly in aortas of CAPtreatment groups $(P<0.05$, Figure 1, A-F).

\section{Discussion}

In this study, we report that hyperglycemia, hypertriglyceridemia, $\mathrm{p} 22^{\text {phox }}$, and gp9 $91^{\text {phox }}$ levels, the major components of NADPH oxidase in rats fed HFD and HSD, were increased in the aorta and that this rise was linked to increased lipid peroxidation and NFKB activities and reduction of Nrf2, Sirt1, and eNOS activities. Supplemental CAPs alleviate the adverse effects of HFD and HSD.

Capsicum has been shown to help improve metabolism and hormone function, ${ }^{27}$ stabilize blood glucose, ${ }^{28}$ and reduce insulin and leptin resistance. ${ }^{29}$ Capsicum and CAPs have also been linked to cardiovascular health, by improving endothelial function, ${ }^{30}$ and inhibiting low-density-lipoprotein cholesterol oxidation. ${ }^{31}$ Capsicum may also help prevent cancer, likely due to its antioxidant activity. ${ }^{32,33}$ The burning sensation associated with capsaicin results from its chemical interaction with sensory neurons. Capsaicin binds selectively to TRPV1, which resides on the membranes of pain- and heat-sensing neurons. ${ }^{34}$ Capsaicin causes an ion channel to open below body temperature, which is why capsaicin is linked to the sensation of heat. Prolonged activation of these neurons by capsaicin depletes presynaptic substance $P$, one of the body's neurotransmitters for pain and heat. The changes observed in this study may have been due to its selective binding to TRPV1; however, further studies need to be carried out in humans. In the current study, it was observed that CAPs reduced total cholesterol, triglycerides, glucose, and insulin in both the HSD and HFD groups. In addition, we observed HSD and HFD enhanced all metabolic health risk factors and increased oxidative stress markers.

CAPs are potent free radical scavengers and prevent membrane stability. ${ }^{35}$ Kogure et al ${ }^{36}$ showed that capsaicin hindered MDA levels and ROS production in rat peritoneal macrophages, as well as inflammatory reactions in sepsis. In addition, chronic exposure to capsaicin depletes neurons of neurotransmitters, reduces pain sensation, and blocks inflammation. ${ }^{37,38}$ In the current study, CAPs increased potential antioxidant properties and demonstrated their ability to protect tissue from damage or inflammation. Similarly, in a previous study, we reported that CAP supplementation elevated the activity of SOD, CAT, and glutathione peroxidase and significantly decreased MDA levels in serum and ovaries. ${ }^{5}$ Kempaiah and Srinivasan ${ }^{39}$ reported that reduced liver antioxidant enzymes, including SOD, CAT, and glutathione peroxidase, in hypercholesterolemic rats were efficiently resisted by capsaicin supplementation $(0.015 \%)$. Lee et al ${ }^{40}$ reported that capsaicin administration for three days reduced 

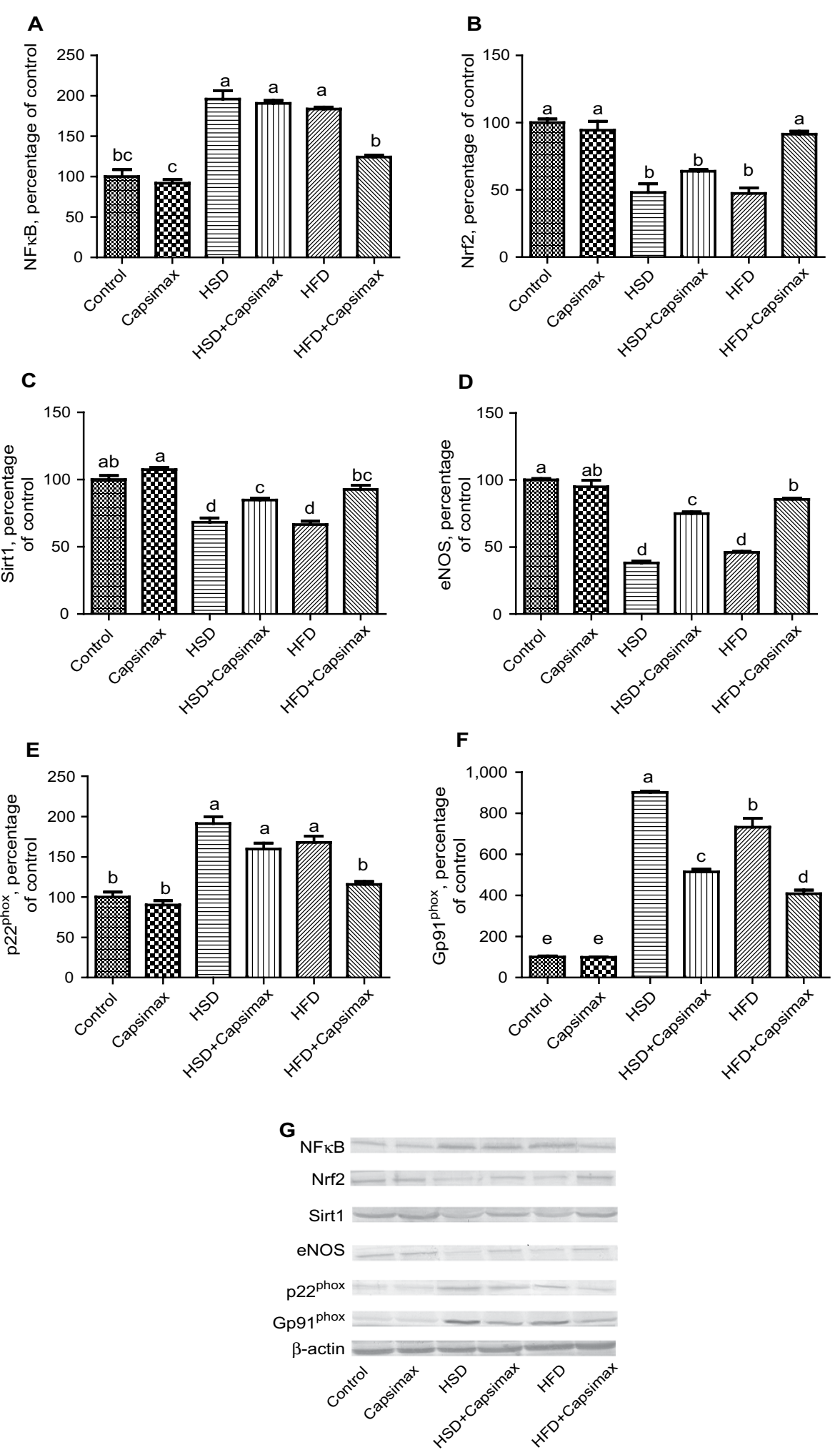

Figure I Effects of capsaicinoids (CAPs) in high-sucrose diet (HSD)- and high-fat diet (HFD)-fed rats.

Notes: Aortic NFKB (A); Nrf2 (B); Sirtl (C); endothelial nitric oxide synthase (eNOS) (D); p22 phox (E); gp9|phox (F). The intensity of the bands was quantified by densitometric analysis. Data expressed as ratio of normal control value (set to $100 \%$ ). Data are expressed as percentage of control value. Each bar represents the mean and standard error of mean. The intensity of the bands $(\mathbf{G})$ was quantified by densitometric analysis. Blots were repeated at least four times, and representative blots are shown. $\beta$-Actin was included to ensure equal protein loading. Different superscripts denote significant differences between groups not sharing the same superscript $(P<0.05)$. Capsimax ${ }^{\circledast}$; OmniActive Health Technologies, Ltd., Morristown, NJ, USA. 
MDA concentration in liver, kidney, muscle, and lung in rats. It is also known that CAPs stimulate energy consumption by activation of the sympathetic nervous system, which induces catecholamine secretion from the adrenal medulla. ${ }^{10,41}$ This thermogenic influence has the advantage of weight management. CAPs have also been reported to decrease appetite, ${ }^{42-44}$ increase thermogenesis, ${ }^{28,45}$ and increase lipolysis, and FFA. ${ }^{10}$ Associations among consumption of CAP-containing food and low incidence of obesity have been reported earlier. ${ }^{10,46}$ CAPs reduce metabolic health risk factors causing obesity and increased energy metabolism. Sirt1 decreases in the HSD and HFD groups indicate that these diets increase the risk of obesity and cardiometabolic syndrome.

The current study revealed different regulatory pathways to prevent oxidative stress, improve antioxidant potential, and enhance energy metabolism (Figure 1). NFאB influenced inflammatory proteins, and CAPs decreased NFאB levels and enhanced Nrf2 activity. In addition, Sirt1 modulates various cellular processes that directly regulate glucose metabolism and stress metabolism, increases fat mobilization and energy metabolism, thereby controlling the direct chromatin structure and stimulating brown remodeling of the white fat in white adipose tissue, regulates pancreatic insulin secretion, detects nutrient availability in the hypothalamus, impairs obesity-induced inflammation in macrophages, and modulates circadian time activity in tissues. ${ }^{47}$ In the current study, CAPs increasing SIRT1 suggest its metabolic role in activating energy metabolism. Further studies are needed to explore this pathway. The thermogenic effect of CAPs is mediated at least in part by a CAP-sensitive structure located in the rostral ventrolateral medulla. ${ }^{48}$ Increased eNOS protein levels in CAP treatment suggest vasoprotection and assistance in reducing cardiovascular risk. CAP treatment may also stimulate vasodilation, ${ }^{30}$ which may indirectly impact thermogenesis, as any resultant loss of heat may necessitate an increase in metabolism. A previous study showed that capsaicin upregulated $\mathrm{HO} 1$ expression by $\mathrm{Nrf} 2$ stimulation in HEPG 2 cells. ${ }^{49}$

Many studies have shown that obesity, HFD intake, hyperglycemia, high tissue lipids, excessive angiotensin II production, and hyperleptinemia can cause vascular damage through numerous metabolic pathways, such as free-radical generation and inflammation. ${ }^{50,51}$ The inflammatory condition of obesity increases leukocyte tissue infiltration and freeradical production, while cytokines are known to upregulate the activity of redox enzymes, including NADPH oxidase (NOX). ${ }^{52}$ NOX is an enzyme system that contains membrane (gp91 $\left.{ }^{\text {phox }}, \mathrm{p} 22^{\text {phox }}\right)$ and cytosolic (p47 $7^{\text {phox }}$, p67 phox,$\left.p 40^{\text {phox }}\right)$ components and produces superoxide, which combines on the plasma membrane to form active oxidase. ${ }^{53}$ Previous studies have suggested that obesity-linked vascular dysfunction is facilitated by NOX-induced oxidative stress. ${ }^{51,54}$ Upregulation of NOX has been related to elevated ROS induced by angiotensin II and TNF $\alpha .{ }^{55,56}$ In previous studies, it has been reported that high glucose incubation upregulates expression of the NADPH subunits $\mathrm{p} 22^{\text {phox }}$ and $\mathrm{p} 67^{\text {phox }}$ in bovine aortic endothelial cells ${ }^{51}$ and in microvascular endothelial cells. ${ }^{57}$ In the current study, the upregulated NADPH oxidase subunits p $22^{\text {phox }}$ and $\mathrm{p} 67^{\text {phox }}$ stimulated by HSD or HFD were decreased by CAP supplementation. The results of this study showed that CAPs might enhance the increased NADPH oxidase levels that result in increased ROS generation, whereas the increase in ROS generation is mostly responsible for the HFD- or HSD-induced endothelial hyperpermeability. Therefore, CAPs inhibited endothelial overpermeability by inhibiting NOX. In addition, Zuo et $\mathrm{al}^{51}$ reported that greentea polyphenols protected against overexpression of high glucose-stimulated p $22^{\text {phox }}$ and p $67^{\text {phox }}$. Akar et al ${ }^{54}$ reported that decreased relaxation to acetylcholine and intensified contractions to phenylephrine and angiotensin II were linked with downregulated eNOS and Sirt1, whereas gp91 ${ }^{\text {phox }}$ and $\mathrm{p} 22^{\text {phox }}$ proteins were upregulated and superoxide production triggered in aortas from high-fructose corn syrup-treated rats. They also reported that resveratrol supplementation efficiently restored high-fructose corn syrup-induced deteriorations.

Several proteins are altered by CAPs, many of which suggest antioxidant properties, reducing oxidative stress and increased metabolism. The results suggest that thermogenesis-and lipid metabolism-associated proteins were significantly changed upon capsaicin administration, suggesting that capsaicin may be a beneficial phytochemical for attenuation of obesity. ${ }^{23}$ CAPs also provide antioxidant activity, which may help protect against inflammatory diseases. In hamsters, CAPs support heart health by lowering cholesterol and increasing blood flow, presumably due to antioxidant activity. ${ }^{58}$ In another study, chili peppers not only reduced total and non-high-density cholesterol and triglycerides but were also related to reduced levels of compounds connected to inflammation, such as Cox $2 .^{59}$

This study further suggests that HSD and HFD diets increase cardiometabolic health risk factors, inflammation, and oxidative stress and reduce potential antioxidant capacity. Therefore, adding CAPs to these diets may help to regulate metabolism and improve antioxidant properties, including reducing metabolic and cardiometabolic health risk factors. 
Further long-term clinical studies are required to show and explore similar findings in humans.

\section{Acknowledgments}

This work was supported by a grant from OmniActive Health Technologies Ltd., India. This work was also supported in part by the Turkish Academy of Sciences.

This paper was presented at the Experimental Biology annual meeting, April 2-6, 2016 in San Diego, CA, USA. Its abstract was published in the FASEB Journal, volume 30, issue 1, supplement 428.7, April 2016.

\section{Disclosure}

VJ is an employee of OmniActive Health Technologies, Inc., NJ, USA. The authors report no other conflicts of interest in this work.

\section{References}

1. Grundy SM. Metabolic syndrome pandemic. Arterioscler Thromb Vasc Biol. 2008;28(4):629-636.

2. Alberti KG, Eckel RH, Grundy SM, et al. Harmonizing the metabolic syndrome: a joint interim statement of the International Diabetes Federation Task Force on Epidemiology and Prevention; National Heart, Lung, and Blood Institute; American Heart Association; World Heart Federation; International Atherosclerosis Society; and International Association for the Study of Obesity. Circulation. 2009;120(16):1640-1645.

3. Molinar-Toribio E, Fuguet E, Ramos-Romero S, et al. A high-fat highsucrose diet affects the long-term metabolic fate of grape proanthocyanidins in rats. Eur J Nutr. Epub 2016 Oct 12.

4. Ishimoto T, Lanspa MA, Rivard CJ, et al. High-fat and high-sucrose (Western) diet induces steatohepatitis that is dependent on fructokinase Hepatology. 2013;58(5): 1632-1643.

5. Sahin K, Orhan C, Akdemir F, et al. $\beta$-Cryptoxanthin ameliorates metabolic risk factors by regulating NF- $\mathrm{KB}$ and Nrf2 pathways in insulin resistance induced by high-fat diet in rodents. Food Chem Toxicol. 2017; 107:270-279.

6. Tuzcu Z, Orhan C, Sahin N, Juturu V, Sahin K. Cinnamon polyphenol extract inhibits hyperlipidemia and inflammation by modulation of transcription factors in high-fat diet-fed rats. Oxid Med Cell Longev. 2017;2017:1583098

7. Yamamoto Y, Oue E. Antihypertensive effect of quercetin in rats fed with a high-fat high-sucrose diet. Biosci Biotechnol Biochem. 2006;70(4):933-939.

8. Liu H, Zhong H, Yin Y, Jiang Z. Genistein has beneficial effects on hepatic steatosis in high fat-high sucrose diet-treated rats. Biomed Pharmacother. 2017;91:964-969.

9. Milton-Laskibar I, Aguirre L, Fernández-Quintela A, et al. Lack of additive effects of resveratrol and energy restriction in the treatment of hepatic steatosis in rats. Nutrients. 2017;9(7):E737.

10. Bloomer RJ, Canale RE, Shastri S, Suvarnapathki S. Effect of oral intake of capsaicinoid beadlets on catecholamine secretion and blood markers of lipolysis in healthy adults: a randomized, placebo controlled, double-blind, cross-over study. Lipids Health Dis. 2010;9:72.

11. Reyes-Escogidode ML, Gonzalez-Mondragon EG, VazquezTzompantzi E. Chemical and pharmacological aspects of capsaicin. Molecules. 2011;16(2):1253-1270.

12. Henning SM, Zhang Y, Seeram NP, et al. Antioxidant capacity and phytochemical content of herbs and spices in dry, fresh and blended herb paste form. Int J Food Sci Nutr. 2011;62(3):219-225.
13. Lu HF, Chen YL, Yang JS, et al. Antitumor activity of capsaicin on human colon cancer cells in vitro and Colo 205 tumor xenografts in vivo. J Agric Food Chem. 2010;58(24):12999-13005.

14. Whiting S, Derbyshire E, Tiwari BK. Capsaicinoids and capsinoids: a potential role for weight management? A systematic review of the evidence. Appetite. 2012;59(2):341-348.

15. Gannon NP, Lambalot EL, Vaughan RA. The effects of capsaicin and capsaicinoid analogs on metabolic molecular targets in highly energetic tissues and cell types. Biofactors. 2016;42(3):229-246.

16. Juturu V. Capsaicinoids modulating cardiometabolic syndrome risk factors: current perspectives. J Nutr Metab. 2016;2016:4986937.

17. Govindarajan VS, Sathyanarayana MN. Capsicum: production, technology, chemistry, and quality - part V: impact on physiology, pharmacology, nutrition, and metabolism; structure, pungency, pain, and desensitization sequences. Crit Rev Food Sci Nutr. 1991;29(6):435-474.

18. Janssens PL, Hursel R, Martens EA, Westerterp-Plantenga MS. Acute effects of capsaicin on energy expenditure and fat oxidation in negative energy balance. PLoS One. 2013;8(7):e67786.

19. Ludy MJ, Moore GE, Mattes RD. The effects of capsaicin and capsiate on energy balance: critical review and meta-analyses of studies in humans. Chem Senses. 2012; 37(2):103-121.

20. Johnson W. Final report on the safety assessment of Capsicum annuum extract, Capsicum annuum fruit extract, Capsicum annuиm resin, Capsicum annuum fruit powder, Capsicum frutescens fruit, Capsicum frutescens fruit extract, Capsicum frutescens resin, and capsaicin. Int J Toxicol. 2007;26(1):3-106.

21. Larqué C, Velasco M, Navarro-Tableros V, et al. Early endocrine and molecular changes in metabolic syndrome models. IUBMB Life. 2011;63(10):831-839.

22. Torres-Villalobos G, Hamdan-Pérez N, Tovar AR, et al. Combined highfat diet and sustained high sucrose consumption promotes NAFLD in a murine model. Ann Hepatol. 2015;14(4):540-546.

23. Joo JI, Kim DH, Choi JW, Yun JW. Proteomic analysis for antiobesity potential of capsaicin on white adipose tissue in rats fed with a high fat diet. J Proteome Res. 2010;9(6):2977-2987.

24. Karatepe M. Simultaneous determination of ascorbic acid and free malondialdehyde in human serum by HPLC-UV. LC GC N Am. 2004;22(4):362-365.

25. Erel O. A novel automated method to measure total antioxidant response against potent free radical reactions. Clin Biochem. 2004;37(2):112-119.

26. Sahin K, Tuzcu M, Orhan C, et al. Anti-diabetic activity of chromium picolinate and biotin in rats with type 2 diabetes induced by high-fat diet and streptozotocin. Br J Nutr. 2013;110(2):197-205.

27. Kang JH, Tsuyoshi G, Le Ngoc H, et al. Dietary capsaicin attenuates metabolic dysregulation in genetically obese diabetic mice. J Med Food. 2011;14(3):310-315.

28. Lejeune MP, Kovacs EM, Westerterp-Plantenga MS. Effect of capsaicin on substrate oxidation and weight maintenance after modest body-weight loss in human subjects. Br J Nutr. 2003;90(3):651-659.

29. Kang JH, Goto T, Han IS, Kawada T, Kim YM, Yu R. Dietary capsaicin reduces obesity-induced insulin resistance and hepatic steatosis in obese mice fed a high-fat diet. Obesity (Silver Spring). 2010;18(4):780-787.

30. Chularojmontri L, Suwatronnakorn M, Wattanapitayakul SK. Influence of capsicum extract and capsaicin on endothelial health. J Med Assoc Thai. 2010;93(2):S92-101.

31. Ahuja KD, Ball MJ. Effects of daily ingestion of chilli on serum lipoprotein oxidation in adult men and women. Br J Nutr. 2006;96(2):239-242.

32. Mori A, Lehmann S, O'Kelly J, et al. Capsaicin, a component of red peppers, inhibits the growth of androgen-independent, p53 mutant prostate cancer cells. Cancer Res. 2006;66(6):3222-3229.

33. Jankovic B, Loblaw DA, Nam R. Capsaicin may slow PSA doubling time: case report and literature review. Can Urol Assoc J. 2010;4(1): E9-E11.

34. Caterina MJ, Schumacher MA, Tominaga M, Rosen TA, Levine JD, Julius D. The capsaicin receptor: a heat-activated ion channel in the pain pathway. Nature. 1997;389(6653):816-824. 
35. Srinivasan K. Biological activities of red pepper (Capsicum annuum) and its pungent principle capsaicin: a review. Crit Rev Food Sci Nutr. 2016;56(9):1488-1500.

36. Kogure K, Goto S, Nishimura M, et al. Mechanism of potent antiperoxidative effect of capsaicin. Biochim Biophys Acta. 2002;1573(1):84-92.

37. Geppetti P, Nassini R, Materazzi S, Benemei S. The concept of neurogenic inflammation. BJU Int. 2008;101(3):2-6.

38. Kissin I. Vanilloid-induced conduction analgesia: selective, dosedependent, long-lasting, with a low level of potential neurotoxicity. Anesth Analg. 2008;107(1):271-281.

39. Kempaiah RK, Srinivasan K. Antioxidant status of red blood cells and liver in hypercholesterolemic rats fed hypolipidemic spices. Int JVitam Nutr Res. 2004;74(3):199-208.

40. Lee CY, Kim M, Yoon SW, Lee CH. Short-term control of capsaicin on blood and oxidative stress of rats in vivo. Phytother Res. 2003; 17(5):454-458.

41. Belza A, Frandsen E, Kondrup J. Body fat loss achieved by stimulation of thermogenesis by a combination of bioactive food ingredients: a placebo-controlled, double-blind 8-week intervention in obese subjects. Int J Obes (Lond). 2007;31(1):121-130.

42. Yoshioka M, St-Pierre S, Drapeau V, et al. Effects of red pepper on appetite and energy intake. Br J Nutr. 1999;82(2):115-123.

43. Yoshioka M, Doucet E, Drapeau V, Dionne I, Tremblay A. Combined effects of red pepper and caffeine consumption on $24 \mathrm{~h}$ energy balance in subjects given free access to foods. Br J Nutr. 2001;85(2):203-211.

44. Westerterp-Plantenga MS, Smeets A, Lejeune MP. Sensory and gastrointestinal satiety effects of capsaicin on food intake. Int J Obes (Lond). 2005;29(6):682-688.

45. Yoshioka M, St-Pierre S, Suzuki M, Tremblay A. Effects of red pepper added to high-fat and high-carbohydrate meals on energy metabolism and substrate utilization in Japanese women. Br J Nutr. 1998;80(6):503-510.

46. Wahlqvist ML, Wattanapenpaiboon N. Hot foods: unexpected help with energy balance? Lancet. 2001;358(9279):348-349.

47. Li X. SIRT1 and energy metabolism. Acta Biochim Biophys Sin (Shanghai). 2013;45(1):51-60.
48. Osaka T, Lee TH, Kobayashi A, Inoue S, Kimura S. Thermogenesis mediated by a capsaicin-sensitive area in the ventrolateral medulla. Neuroreport. 2000;11(11):2425-2428.

49. Joung EJ, Li MH, Lee HG, et al. Capsaicin induces heme oxygenase-1 expression in HepG2 cells via activation of PI3K-Nrf2 signaling: $\mathrm{NAD}(\mathrm{P}) \mathrm{H}$ :quinone oxidoreductase as a potential target. Antioxid Redox Signal. 2007;9(12):2087-2098.

50. Vincent HK, Taylor AG. Biomarkers and potential mechanisms of obesity-induced oxidant stress in humans. Int $J$ Obes (Lond). 2006;30(3):400-418.

51. Zuo X, Tian C, Zhao N, et al. Tea polyphenols alleviate high fat and high glucose-induced endothelial hyperpermeability by attenuating ROS production via NADPH oxidase pathway. BMC Res Notes. 2014;2:7-120.

52. Cave AC, Brewer AC, Narayanapanicker A, et al. NADPH oxidases in cardiovascular health and disease. Antioxid Redox Signal. 2006;8(5-6):691-728.

53. Deleo FR, Quinn MT. Assembly of the phagocyte NADPH oxidase: molecular interaction of oxidase proteins. J Leukoc Biol. 1996;60(6):677-691.

54. Akar F, Uludağ O, Aydın A, et al. High-fructose corn syrup causes vascular dysfunction associated with metabolic disturbance in rats: protective effect of resveratrol. Food Chem Toxicol. 2012;50(6):2135-2141.

55. Ying CJ, Xu JW, Ikeda K, Takahashi K, Nara Y, Yamori Y. Tea polyphenols regulate nicotinamide adenine dinucleotide phosphate oxidase subunit expression and ameliorate angiotensin II-induced hyperpermeability in endothelial cells. Hypertens Res. 2003;26(10):823-828.

56. Zhang WF, Xu YY, Xu KP, et al. Inhibitory effect of selaginellin on high glucose-induced apoptosis in differentiated PC12 cells: role of NADPH oxidase and LOX-1. Eur J Pharmacol. 2012;694(1-3):60-68.

57. Ding H, Aljofan M, Triggle CR. Oxidative stress and increased eNOS and NADPH oxidase expression in mouse microvessel endothelial cells. J Cell Physiol. 2007;212(3):682-689.

58. Chen J, Li L, Li Y, et al. Activation of TRPV1 channel by dietary capsaicin improves visceral fat remodeling through connexin43-mediated Ca2+ influx. Cardiovasc Diabetol. 2015;14:22.

59. Liang YT, Tian XY, Chen JN, et al. Capsaicinoids lower plasma cholesterol and improve endothelial function in hamsters. Eur J Nutr. 2013;52(1):379-388.
Journal of Inflammation Research

\section{Publish your work in this journal}

The Journal of Inflammation Research is an international, peer-reviewed open access journal that welcomes laboratory and clinical findings on the molecular basis, cell biology and pharmacology of inflammation including original research, reviews, symposium reports, hypothesis formation and commentaries on: acute/chronic inflammation; mediators of

\section{Dovepress}

inflammation; cellular processes; molecular mechanisms; pharmacology and novel anti-inflammatory drugs; clinical conditions involving inflammation. The manuscript management system is completely online and includes a very quick and fair peer-review system. Visit http://www.dove press.com/testimonials.php to read real quotes from published authors. 